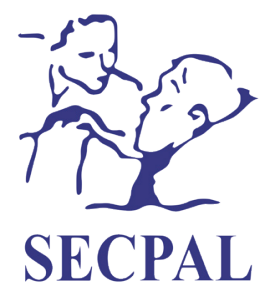

\title{
Medicina Paliativa
}

www.medicinapaliativa.es

\section{CARTAS AL DIRECTOR}

\section{Dolor en la enfermedad renal avanzada: síntoma frecuente e inexplorado}

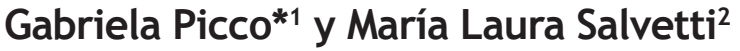

\begin{abstract}
${ }^{1}$ Médico Internista- Paliativista, Unidad de Cuidados Paliativos, Hospital San Juan de Dios, Pamplona. ${ }^{2}$ Médico Internista y Nefróloga, Servicio de Nefrología, Complejo Universitario de Navarra, Pamplona. España
\end{abstract}

Recibido el 28 de septiembre de 2017

Aceptado el 04 de octubre de 2017

Picco G, Salvetti ML. Dolor en la enfermedad renal avanzada: síntoma frecuente e inexplorado. Med Paliat. 2019;26(1):91-92.

\section{Sr. Director:}

A propósito de la lectura del artículo de Miguel y cols. ${ }^{1}$ sobre "Cómo son los últimos meses de vida de los pacientes con insuficiencia renal avanzada", llama la atención que las autoras concluyan que "... Los síntomas más frecuentemente encontrados fueron el insomnio, la tristeza, la disnea y el prurito, además de la presencia de edemas", sin mencionar el dolor que según la bibliografía es uno de los síntomas más comunes experimentados por pacientes con insuficiencia renal crónica avanzada (ERCA) $)^{2,3}$.

Durante años se consideró a la muerte por encefalopatía urémica "indolora", ya que un grupo de pacientes fallecen en coma, pero estudios prospectivos hechos al suspender la diálisis indican que el dolor es el más común de los síntomas de pacientes al final de la vida y que, en general, es muy severo $0^{2,3}$.

El 50-60\% de los pacientes refieren padecer dolor crónico; 42-55\% de estos pacientes califican su dolor como severo ${ }^{2,3}$. Los pacientes con ERCA y cáncer tienen tasas similares de dolor moderado a severo $(53,7 \% \text { vs. } 57,8 \% \text {; } p=0,34)^{4}$.

Esta infravaloración conduce a un inadecuado tratamiento del dolor que, en la mayor parte de los casos, es de origen musculoesquelético, y con menor frecuencia es de origen neuropático o vascular. Las principales consecuencias del dolor no tratado son el insomnio y la depresión; ambos fueron aspectos registrados en el estudio de de Miguel y cols. como principales síntomas hallados, pero no mencionan que estén vinculados a dolor ${ }^{1-3}$.

Murtagh y cols. ${ }^{2}$ han estudiado la prevalencia y la severidad de síntomas en el mes previo a la muerte en pacientes con ERC en estadio 5, manejados sin diálisis utilizando el Memorial Symptom Assessment Scale-Short Form (MSAS-SF) y de los 74 pacientes que participaron en el estudio, con una edad media de 81 años, el $86 \%$ refería astenia severa, el $84 \%$ prurito, el $80 \%$ disnea, el $73 \%$ dolor y el $71 \%$ presentaban edemas de brazos o piernas. El ensayo clínico aleatorizado SMILE (Symptom Management Involving End-Stage Renal Disease) señala el dolor y la depresión en pacientes renales avanzados como los síntomas de mayor prevalencia y más subdiagnosticados ${ }^{3-6}$.

Fentanilo y metadona son los fármacos de elección para el tratamiento del dolor y la disnea en pacientes al final de la vida en los que se ha suspendido la diálisis ${ }^{5,6}$.

Los pacientes renales que se sitúan en escenarios de final de vida conforman un grupo de especial riesgo debido a la alta vulnerabilidad y dependencia a la que se enfrentan, y el estudio y manejo del dolor es una prioridad que debe promoverse tanto en el ejercicio clínico como en investigación ${ }^{6}$.

\footnotetext{
*Autor para correspondencia:

Gabriela Picco

Unidad de Cuidados Paliativos. Hospital San Juan de Dios. c/ Beloso Alto, 3. 31006, Pamplona, Navarra, España

Correo electrónico: abpicco@hotmail.com
} 


\section{Bibliografía}

1. De Miguel C, Morán C, Rumayor M, Fernández B, del Cura I, Sanz $E M$, et al. ¿Cómo son los últimos meses de vida de los pacientes con insuficiencia renal crónica avanzada en los que se desestima el tratamiento con hemodiálisis o con diálisis peritoneal? Med Paliat. 2018;25(2):83-94.

2. Murtagh FE, Addington-Hall J, Edmonds P, Donohoe P, Carey I, Jenkins K, et al. Symptons in the month before death for stage 5 chronic kidney disease patients managed without dialysis. J Pain Sympton Manage. 2010;40(3):342-52.
3. Davidson SN. The prevalence and management of chronic pain in end stage renal disease . J Palliat Med. 2007;10(6):1277-87.

4. Wachterman MW, Lipsitz SR, Lorenz KA, Marcantonio ER, Li Z, Keating NL. End-of-Life Experience of Older Adults Dying of End-Stage Renal Disease: A Comparison With Cancer. J Pain Symptom Manage. 2017;54(6):789-97.

5. Cohen LM, Germain M, Poppel DM, Woods A, Kjellstrand CM. Dialysis discontinuation and palliative care. Am J Kidney Dis 2000;36(1):140-4.

6. Koncicki HM, Unruh M, Schell JO. Pain Management in CKD: A Guide for Nephrology Providers.Am J Kidney Dis. 2017;69(3):451-60. 